\title{
A Comparison of Materials Issues for Cermet and Graphite- Based NTP Fuels
}

\author{
M. E. M. Stewart ${ }^{1}$ \\ VPL at NASA Glenn Research Center, Cleveland, Ohio, 44135 \\ Bruce G. Schnitzler ${ }^{2}$ \\ Formerly of Idaho National Laboratory, Idaho Falls, Idaho, 83415-3870
}

\begin{abstract}
This paper compares material issues for cermet and graphite fuel elements. In particular, two issues in NTP fuel element performance are considered here: ductile to brittle transition in relation to crack propagation, and orificing individual coolant channels in fuel elements. Their relevance to fuel element performance is supported by considering material properties, experimental data, and results from multidisciplinary fluid/thermal/structural simulations. Ductile to brittle transition results in a fuel element region prone to brittle fracture under stress, while outside this region, stresses lead to deformation and resilience under stress. Poor coolant distribution between fuel element channels can increase stresses in certain channels. NERVA fuel element experimental results are consistent with this interpretation. An understanding of these mechanisms will help interpret fuel element testing results.
\end{abstract}

\section{Nomenclature}

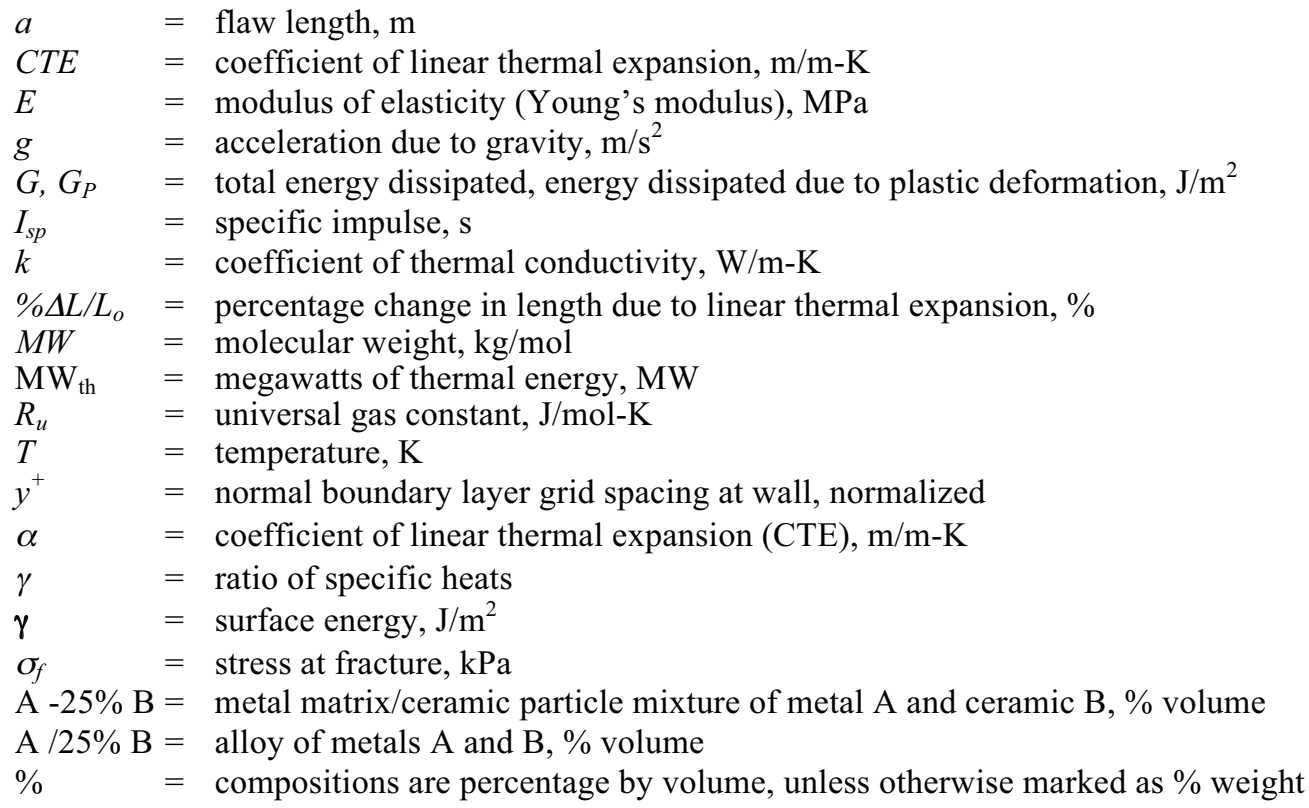

\section{Introduction}

Wuclear Thermal Propulsion (NTP) is a technology for high-thrust, in-space propulsion. It is similar to conventional chemical propulsion except that it uses a nuclear fission reaction- not a chemical reaction- to

\footnotetext{
${ }^{1}$ Senior Research Engineer, 21000 Brookpark Road, MS VPL-3, AIAA Member.

${ }^{2}$ Post Office Box 2274, Idaho Falls, ID, 83403, AIAA Senior Member.
} 
heat the hydrogen propellant. Equation (1) shows that, for an ideal gas, the low molecular weight, $M W$, of the hydrogen propellant-2/18 of LOX/LH2 - gives significantly better efficiency, or specific impulse $I_{s p}$, than chemical propulsion.

$$
I_{s p}=\frac{1}{g} \sqrt{\frac{2 \gamma}{\gamma-1} \frac{R_{u}}{M W} T}
$$

NTP doesn't achieve three times the $I_{s p}$ as $\mathrm{MW}_{\mathrm{H} 2} / \mathrm{MW}_{\mathrm{H} 2 \mathrm{O}}$ would suggest. Dissociation and ionization of $\mathrm{H}_{2}$ and $\mathrm{H}_{2} \mathrm{O}$ propellants differ. Chemical rockets achieve a higher propellant temperature within the gas by keeping the peak temperatures away from walls. With NTP, fission heat is generated in the solid fuel and must be transferred to the gaseous propellant through coolant channels in the fuel; this solid fuel must remain intact and not melt, so the fuel is designed to thermal and structural limits. Reference [1] explains the how high specific impulse, $I_{s p}$, is achieved and gives a history.

In two large research programs, thermal spectrum, propulsion reactors with graphite-based fuels were developed as a series of reactors was designed, built and tested. In 1955 the Rover program was initiated, followed in 1961 by NASA's NERVA (Nuclear Engine for Rocket Vehicle Applications) program. Excellent histories of the Rover and NERVA programs are given in Refs. [2] and [3]. The most promising, tested graphite-based fuel design was uranium and zirconium carbide in solid solution in graphite, denoted $(\mathrm{U}, \mathrm{Zr}) \mathrm{C}$ - graphite composite, with a zirconium carbide coating for coolant channels and the exterior surface.

NTP rockets with cermet fuel elements in fast spectrum reactors were also designed, but not extensively built or tested. In the 1960's, Argonne National Laboratory designed the ANL200 [4] and ANL2000 engines-200 MW th and $2000 \mathrm{MW}_{\text {th }}$ fast spectrum propulsion reactors. Considerable basic materials research was done at NASA, DOE, and corporate laboratories to characterize cermet fuel behavior. Notable work includes [4], [5], [6], and [7]. Ref. [8] provides an overview of this research plus an analysis of methods for reducing fuel loss. A cermet (ceramic metallic) is formed when a mixture of metal powder and ceramic powder or particles (all of microscopic size) are compressed at high temperatures; the result is a metallic matrix containing ceramic particles. The ANL200 reactor design was based on a $\mathrm{W}-60 \% \mathrm{UO}_{2}-6 \% \mathrm{Gd}_{2} \mathrm{O}_{3}$ fuel with a $\mathrm{W} / 25 \%$ Re cladding.

\section{A. Graphite-Based and Cermet Fuel Testing:}

Extensive testing proved and improved the design and manufacture of NERVA fuel elements. The high water mark of graphite-based fuel testing was the Nuclear Furnace-1 (NF-1) test of (U, Zr)C — graphite composite fuel [9] [10]. This fuel demonstrated reduced erosion of the coolant channel coating and underlying graphite, and the cause involves stresses arising from a mismatch between the coefficient of thermal expansion (CTE) of the coating and fuel. Despite efforts to increase the $\mathrm{CTE}$ of the $(\mathrm{U}, \mathrm{Zr}) \mathrm{C}$ - graphite composite fuel to better match the $\mathrm{ZrC}$ coating, NF-1 results show some remaining erosion. Figure 1 shows mass loss versus length for two fuel elements, and the mid-passage erosion is clear. Figure 2 is a photograph of the mid-passage erosion region from a NERVA graphite fuel element from the NF-1 test. The photograph shows that center coolant channels experienced $\mathrm{ZrC}$ coating cracks while edge channels retained their coatings. There are cracks about the circumference of the channelsuggesting an axial tensile stress. Further, there are longitudinal cracks in the channel-suggesting circumferential tensile stress around the channel.

Soon after the NF-1 test was conducted in 1972, the Rover/NERVA program ended. The cause of this midpassage erosion has remained unresolved, and it is significant since it is a reactor life limiting, in particular, the loss of moderating graphite reduces the reactivity of the reactor. Structural consequences may also be important.

Cermet fuel testing was more limited than NERVA graphite fuel testing. No reactor tests were done, but there was thermal cycling testing. The GE 710 Program [7] was a reactor materials testing and development program for high temperature $(>2200 \mathrm{~K})$, fast spectrum, gas reactors. It included extensive thermal cycling of material samples of $\mathrm{W}-60 \% \mathrm{UO}_{2}$ fuel (some with $\mathrm{ThO}_{2}$ stabilizer) and Ta cladding before using $\mathrm{W} / 30 \% \mathrm{Re} / 30 \% \mathrm{Mo}$ alloy cladding [11]. In perhaps the most significant tests, the ANL200/2000 program [4, p. 147] claimed it was "possible to consistently produce (1) $10 \mathrm{~m} / \mathrm{o} \mathrm{GdO}{ }_{1.5}$ stabilized, $\mathrm{W}-60 \mathrm{v} / \mathrm{o} \mathrm{UO} \mathrm{U}_{2}$ cermets clad with tungsten by vapor deposition that can withstand about 193 cycles (49 total hours) to $2500 \mathrm{C}\left(2800 \mathrm{~K}\right.$ ) and (2) $10 \mathrm{~m} / \mathrm{o} \mathrm{GdO}_{1.5}$ stabilized, W $-60 \mathrm{v} / \mathrm{o} \mathrm{UO}_{2}$ cermets clad with wrought W-25w/o Re by pressure bonding that can withstand about 70 cycles $(18 \mathrm{hr})$ to $2700 \mathrm{C}$ $(3000 \mathrm{~K})$, both with a fuel loss of one percent" in flowing hydrogen. The tungsten CVD process and thermal cycling results are detailed in [12, pp. 17-20]. Figure 3 shows thermal cycling results at various temperatures. Pictures of 

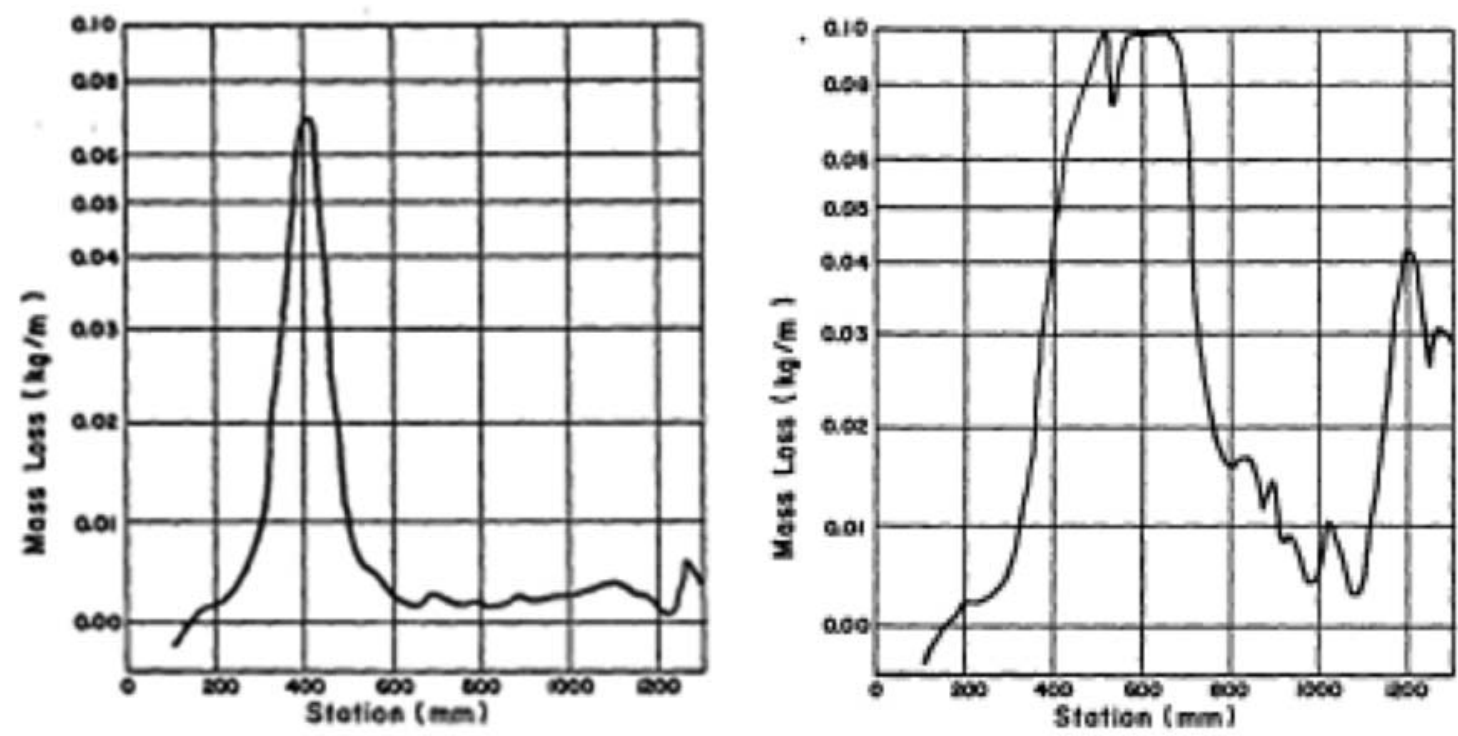

Figure 1. Mass loss versus length for $(\mathrm{U}, \mathrm{Zr}) \mathrm{C}$ - graphite elements with a thermal expansion of $>6.5 \mu \mathrm{m} / \mathrm{mK}$ (left) and $6.1 \mu \mathrm{m} / \mathrm{mK}$ (right) at $2000 \mathrm{~K}$. From Reference [9, p. 7]. The fuel element at left was essentially crack free after fabrication and reactor installation, while the right element would have cracked during cooldown from fabrication.

failed fuel elements [13, p. 111] show ("blistering" or "severe blistering") of the external tungsten cladding, which may be due to buckling of the cladding under the compressive force that develop during cooldown.

Among cermet fuels, testing demonstrated the superiority of tungsten coated uranium dioxide particles in a metal matrix. Uranium dioxide has a high vapor pressure (vaporizes) at temperatures above 2200K [14], and the tungsten coating retained the $\mathrm{UO}_{2}$. Further, tungsten-uranium dioxide dispersions have a high ductile to brittle transition temperature and are brittle for much more for the operating temperature range (Table 1). Analysis and testing revealed gadolinium oxide, $\mathrm{Gd}_{2} \mathrm{O}_{3}$, provides structural stability to uranium dioxide [8] [15]. It "results in the suppression of the $\mathrm{UO}_{2}$-hydrogen reactions and this results in increased structural stability of the $\mathrm{W}-\mathrm{UO}_{2}$ cermets" [4, p. 147].

These thermal cycling test results for cermet fuels are valuable, but they are not comprehensive tests. Heating fuel elements in a furnace with flowing hydrogen involves stresses due to CTE mismatch at the hold temperature, however they do not capture thermal stresses due to heat flow and temperature gradients through the fuel matrix to the coolant channel. Further, they will not catch the tendency of cracks to propagate at temperatures below the ductile to brittle transition temperature.

The next section explains these sources of stress in fuel elements-both cermet and graphite-based fuels. Section III concerns orificing the individual coolant channels in the fuel element, and how preserved and cracked channel coatings (Figure 2) might occur. Section IV explains why a brittle region can exist in fuel elements, and how a material can change from brittle to ductile when temperatures are reached where plasticity is present. Section V reviews the multidisciplinary fluid/thermal/structural simulation methods.

\section{Stress Sources in NTP Fuel Elements}

Two major sources of fuel element stress both arise from thermal expansion effects: CTE mismatch and thermal stresses. As temperatures change, different materials expand/contract by different amounts. Figure 4 quantifies this expansion of component materials found in both cermet and graphite fuels. The curves cross at $1500 \mathrm{~K}$ where the material is assumed to be stress-free after fabrication.

Other sources of stress exist in fuel elements, but they are small or not considered here. During testing, the installation of the fuel element must allow for thermal expansion. Unsupported sections of the fuel element will have stresses. For comparison, an ANL200 fuel element supported at its end has an estimated maximum stress of 4 


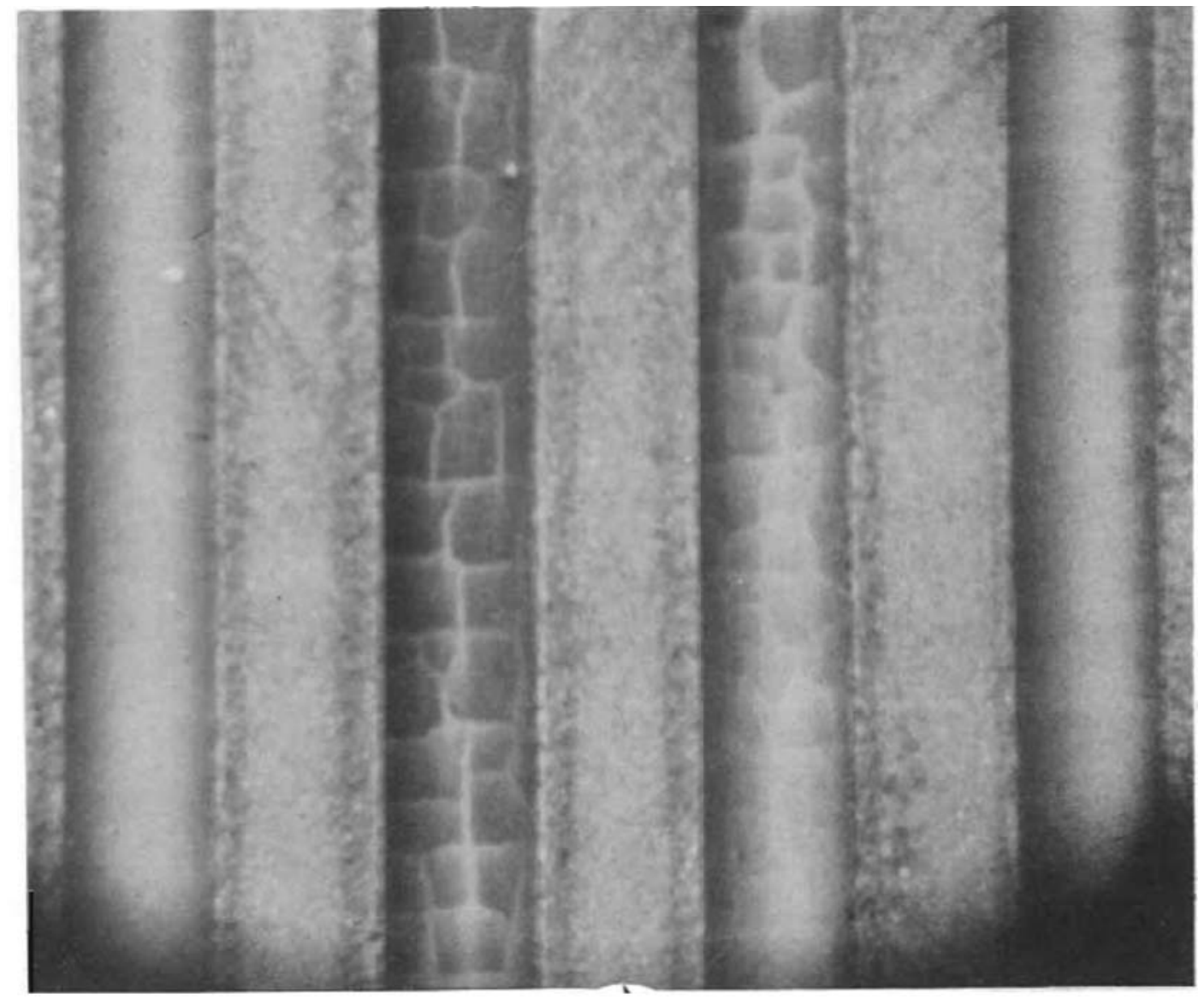

Figure 2. Center coolant channels experienced coating cracks in the Nuclear Furnace-1 test while edge channels retained their coatings. Coating cracking is in the mid-passage erosion region of this NERVA (U, Zr)C-graphite composite fuel element. Estimated mean fuel temperature 1400-1500 K. Photo from Ref. [9, p. 8].

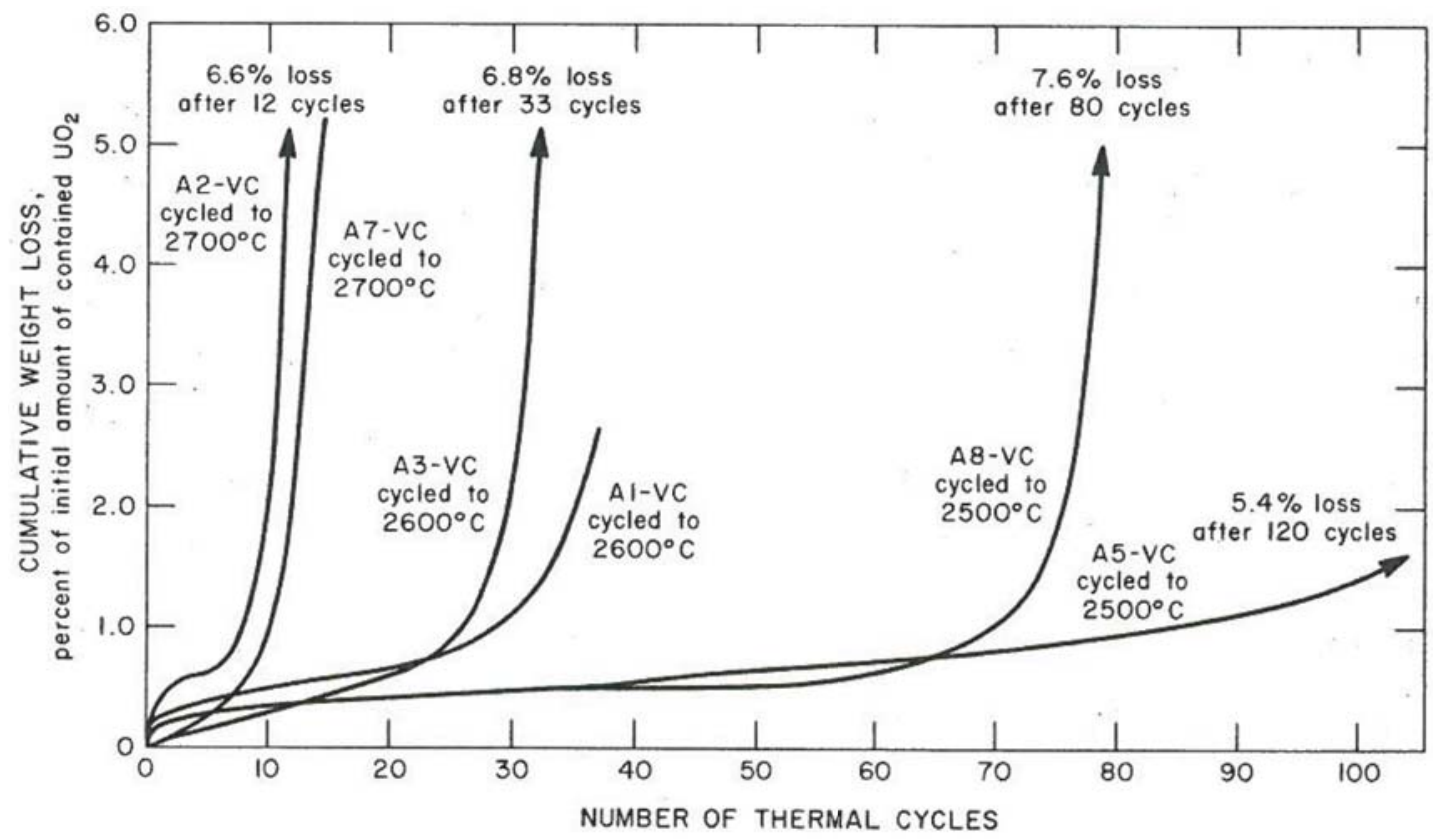

Figure 3. Fuel-loss behaviors of tungsten-clad $\mathrm{W}-66 \% \mathrm{v} / \mathrm{o}\left(10 \mathrm{~m} / \mathrm{o} \mathbf{G d O}_{1.5}\right.$-stabilized $\left.\mathrm{UO}_{2}\right)$ cermets thermally cycled to $2500 \mathrm{C}$, to $2600 \mathrm{C}$, and to $2700 \mathrm{C}$. From Ref. [13, p. 105]. 

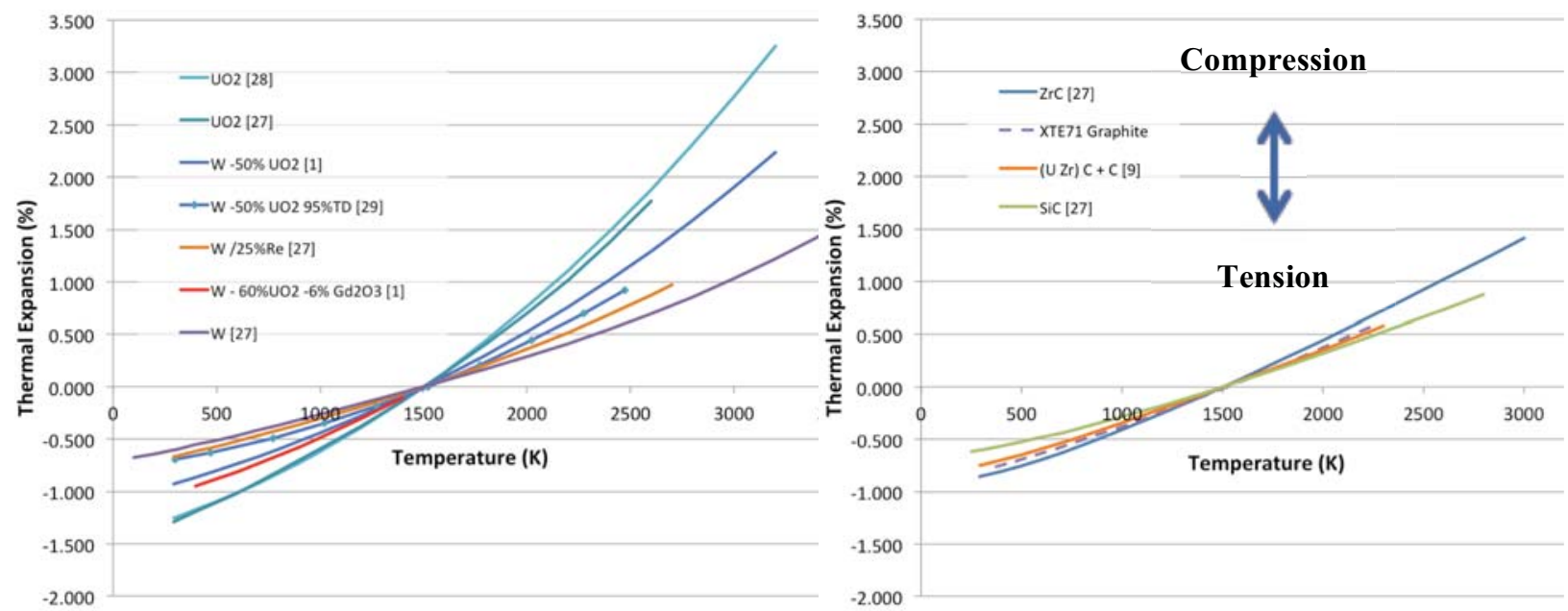

Figure 4. Comparison of linear thermal expansion, $\% \Delta L / L_{o}$, for cermet (left) and graphite-based (right) reactor materials. At a temperature, for CTE mismatch the curve of the material in compression is above the curve of the material in tension. Values may depend on crystal structure and fabrication techniques. $1500 \mathrm{~K}$ is chosen here as the zero stress condition, and the curves cross.

MPa. Stresses from bending and interaction with other fuel elements may cause significant stresses, but are not considered here.

\section{A. CTE Mismatch Stresses}

As temperatures increase, different materials thermally expand by different amounts; where they are bonded - as in a coating-stresses are necessary to maintain both equal expansion and the bond. The stresses in both materials oppose each other, one side is in compression, the other in tension. During startup and cooldown, this stress reverses each time temperature passes the stress-free point, hence each cycle has each bonded material both in tension and compression. This stress cycling can weaken the interface bond by growing and accumulating defects and cracks. At high enough temperatures and stresses, these stresses create permanent deformation (plastic and creep deformation) near the fuel/coating interface. On cooldown, the stresses reverse, deformation approximately reverses, but material deformation accumulates and the coating bond weakens.

Interestingly, coatings for cermet and graphite fuel elements have opposite CTE mismatch stresses: the $\mathrm{ZrC}$ coating of $(\mathrm{U}, \mathrm{Zr}) \mathrm{C}$ - graphite fuel elements is in tension on cooldown, while the $\mathrm{W} / 25 \%$ Re cladding of ANL 200 fuel elements is in compression. Figure 4 demonstrates this effect. On cooldown, the $\mathrm{ZrC}$ coating of NERVA graphite fuels are prone to cracking, while the $\mathrm{W} / 25 \%$ Re cladding is prone to buckling, seen as blistering.

\section{B. Thermal Stresses}

Thermal stresses arise from temperature gradients that lead to variations in material expansion and the need for stresses to maintain shape. Figure 5 shows the temperature distribution when nuclear heat is deposited uniformly within the fuel; temperature peaks between coolant tubes. In fact, heat moves down a temperature gradient to the coolant channel surface (with slope of thermal conductivity, $k$ ), and this gradient is $\sim 30$ times the axial temperature gradient that peaks near $5000 \mathrm{~K} / \mathrm{m}$. This difference in temperature in between coolant channels, creates a difference in thermal expansion, and a stress is needed to preserve shape. In Figure 5, the hotter fuel matrix is in compression.

Figure 5 also shows the high temperature on the fuel element edge and the resultant stress. Fuel element geometry creates a larger volume at the edge, hence larger amounts of heat must be drained into adjacent coolant channels. This larger temperature gradient creates larger thermal stresses. Edge heating and stresses were carefully considered and simulated in the ANL 200/2000 program [4, p. 37].

A previous paper [1] estimated thermal conductivity, $k$, for NERVA graphite and cermet fuels; (U,Zr)Cgraphite and $\mathrm{W}-50 \% \mathrm{UO}_{2}$ have comparable thermal conductivity, hence the slope of the temperature gradient is similar in both fuels. The peak heat deposition rate in the ANL200 simulation [1] is $7.3 \mathrm{MW} / \mathrm{L}$, while for the NERVA fuel element simulations [16] it is $4.7 \mathrm{MW} / \mathrm{L}$. 

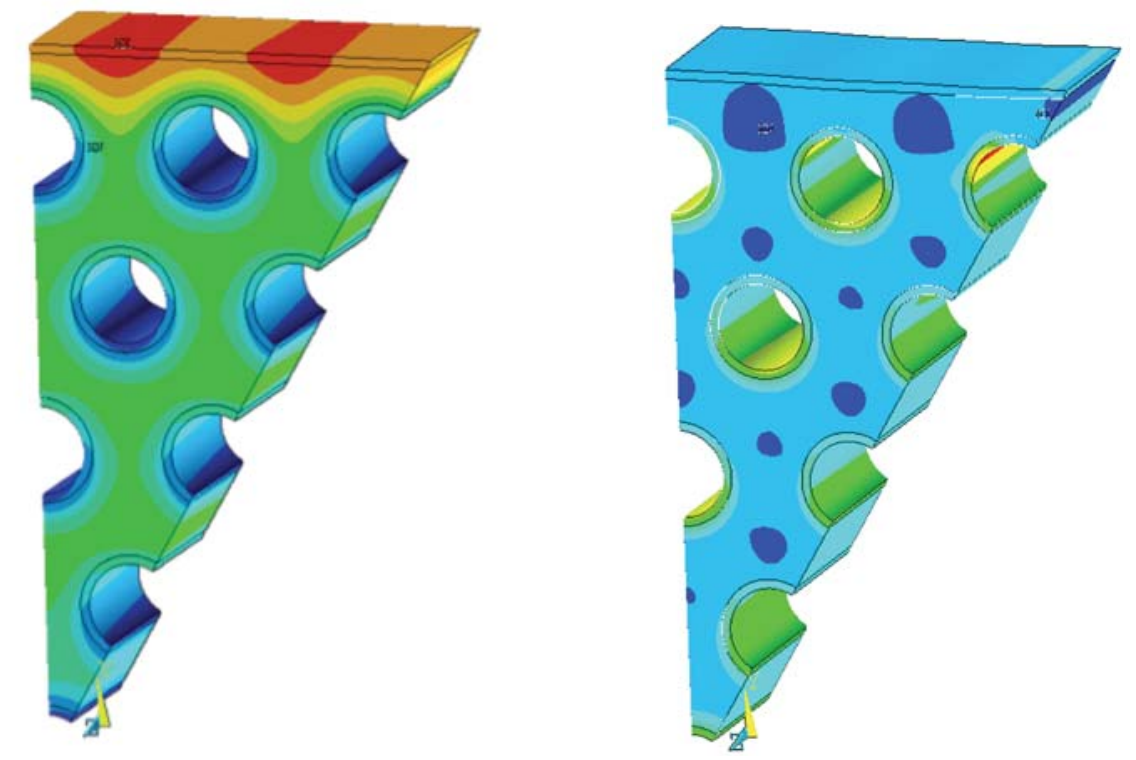

Figure 5. Temperature distribution (left) and first principal stress (right) for an ANL200 cermet fuel element cross-sectional model. Larger volume on the fuel element edge means more heat drains into edge channels, hence temperatures and thermal stresses are higher. At right, blue indicates compression which peaks on the hot edge. Temperature range is $1500 \mathrm{~K} \pm 266 \mathrm{~K}$; elastic stress range is -572 to $946 \mathrm{MPa}$. Near the stress-free temperature, CTE mismatch stresses are small. Heat deposition $5 \mathrm{MW} / \mathrm{L}$.

\section{The Need for Coolant Channel Orificing}

Orificing of individual coolant channels may be needed since some channels-edge channels in particularoperate at higher fuel and channel propellant temperatures, and higher pressure drops. Figure 5 demonstrates the high temperatures on the fuel element edge, and the accompanying thermal stresses.

In full fuel element simulations, variations of $100 \mathrm{~K}$ in the mean coolant outflow temperature are seen in current fluid/thermal/structural simulations with identical coolant flow in each channel [1] [16]. Instead, if identical pressure drop is imposed on all coolant channels (a more realistic condition), edge channels tend to be starved of coolant that bypasses to interior channels and thermal stresses become worse.

Importantly, orificing allows a higher mean propellant temperature for the same maximum fuel temperature. Orificing is also studied here to see if a lack of orificing creates temperature variations that contribute to additional stress and cracking in specific coolant channels (Figure 2).

The ANL200/ANL2000 design thinking [4, p. 119] about coolant channel orificing was:

"Compensation for the nonuniform power profile was provided by orificing the flow to each fuel element. It was initially assumed that regulation of the coolant flow to each fuel element would suffice; however, an analysis performed on this basis indicated that the orificing of each coolant hole (or radial variation of the hole diameters) is required. The feasibility of orificing individual coolant channels has been demonstrated in practice with the NERVA reactor system, for which flow testing of each fuel-element coolant channel prior to core assembly and test firing insures that the required orificing is accomplished. If a premium is placed on the minimization of system weight, the effort expended in orificing the fuel element flow channels is justified."

In the NERVA Small Nuclear Rocket Engine (SNRE) design reports [17], little is said about orificing. The least cryptic comment found about orificing individual coolant channels is, "Each fuel channel in the 364 computer model was orificed to obtain an equal exit-gas temperature. This causes the outside holes to be hotter at mid-station because of the increasing conduction downstream in the center element." 


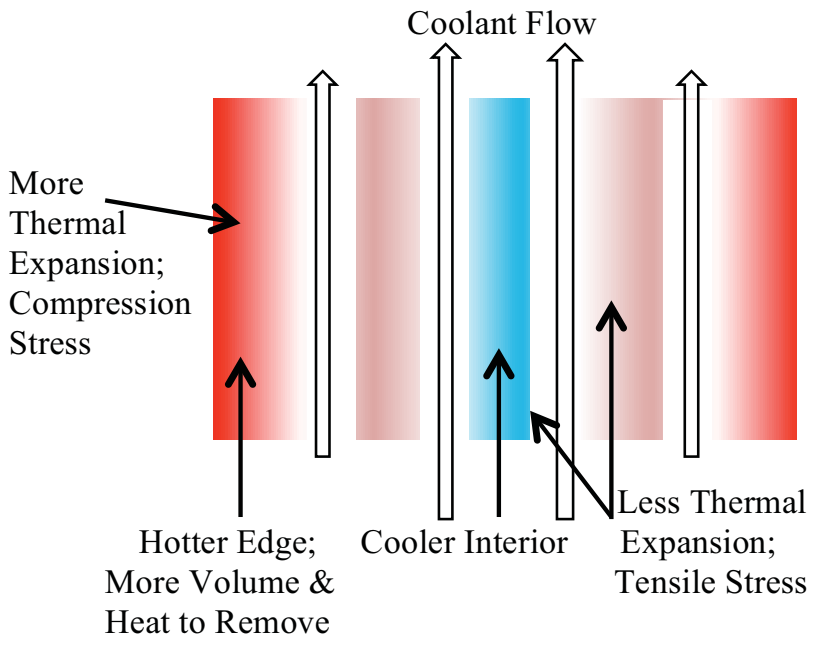

Figure 6. Fuel element cross section showing temperature variation and extra compressive and tensile stresses. Larger edge volume means edge coolant channels have more heat to remove and are at higher temperatures than the interior. Due to different amounts of thermal expansion, extra compressive stress occurs on the edge, and extra tensile stress occurs in the interior. Coolant tends to bypass to interior channels.

The possibility of hotter edge coolant channels raises an interesting question. Figure 2 is a photograph of mid-passage erosion from a NERVA graphite fuel element from the NF-1 test. The photograph shows that center coolant channels experienced coating cracks in this test while edge channels retained their coatings. There are cracks about the circumference of the interior channel-suggesting an axial tensile stress. Further, there are longitudinal cracks in the channel-suggesting circumferential tensile stress around the channel.

A simple explanation may exist if the fuel element's coolant channels were not perfectly orificed (Figure 6). The fuel around hotter edge coolant channels would thermally expand more than around interior channels. To compensate for this difference in thermal expansion, an additional stress must exist that is compressive around edge channels and tensile around interior channels. Yet this compressive stress would protect edge channel coatings (compression reduces tension), while the tensile stress would compromise the coatings of adjacent interior channels (tension adds to tension). Figure 7 shows simulation predictions for plastic deformation in the NERVA (U,Zr)C - graphite composite fuel element with and without edge heating. The interior coolant passages have additional tensile stress and go beyond the yield point, while the edge coolant passages have a reduced tensile stress and are protected.
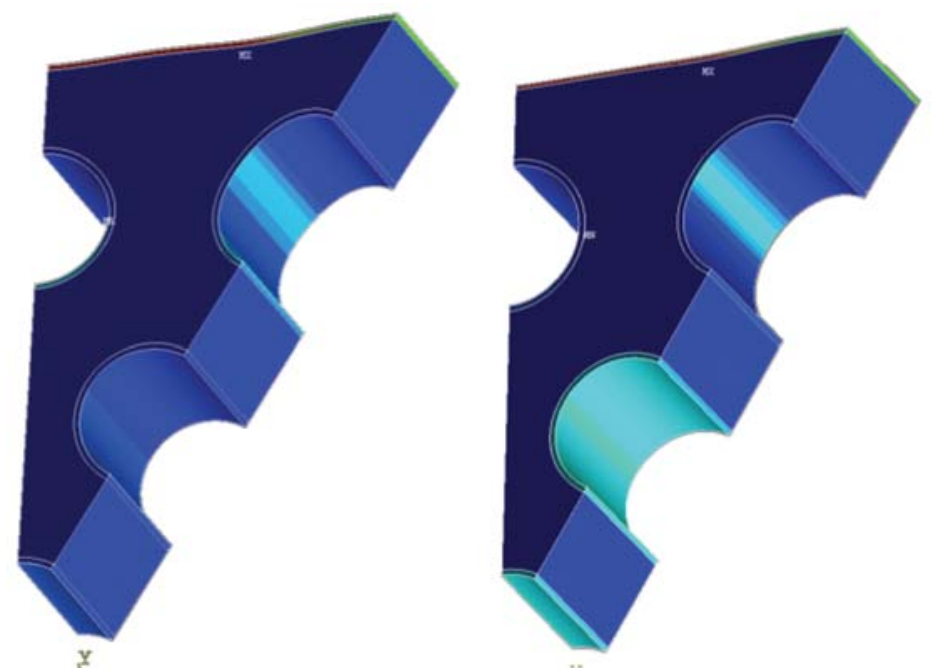

Figure 7. Simulation predictions of von Mises plastic strain in two cases: with similar edge and interior coolant channel temperature (left) and $100 \mathrm{~K}$ higher edge channel temperature (right). At these temperatures, near $1300 \mathrm{~K}$, plastic strain-or strain beyond yield-will result in fracture; ductile deformation occurs at higher temperatures. Hot fuel element edges create extra compression on edges and tensile stress in interior channel coatings that is sufficient for fracture. NERVA (U,Zr)C-graphite composite fuel element at 5 $M W / L$. 


\section{Ductile to Brittle Transition Temperature, Plasticity, and Fracture}

Ductile to brittle transition temperature (DBTT) is a property of metals where fracture properties change dramatically at a temperature. Below this temperature, cracks are prone to propagate and the material to shatter. Above this temperature, the propagation of cracks is impeded, and the material is ductile (and/or malleable), that is, it tends to deform without breaking under tension (or compression). In particular, as temperature increases, plasticity appears, and plastic deformation blunts or shields the crack tip. Ductility and malleability are important in metalworking; when cracking occurs at room temperature, heating past this transition eases shaping and avoids breakage. Table 1 shows temperatures where plasticity appears.

\begin{tabular}{|l|c|c|c|}
\hline & $\begin{array}{c}\text { Transition } \\
\text { Temperature } \\
(\mathbf{K})\end{array}$ & Criteria/Reference & Form/Fabrication \\
\hline Zirconium Carbide, $\mathrm{ZrC}$ & $1400-1500$ & Signs of Plasticity/ [19] [20] & Crystal/Polycrystalline \\
\hline Tungsten Rhenium, W $/ 25 \mathrm{Re}$ & 350 & $5 \%$ Elongation/ [21] & Arc-Melted, Extruded \& Swaged \\
\hline Tungsten, W & 530 & $5 \%$ Elongation/ [21] & Arc-Melted, Extruded \& Swaged \\
\hline $\mathrm{W} \mathrm{10 \%} \mathrm{vol} \mathrm{UO} \mathrm{U}_{2}$ Dispersion & 530 & {$[5]$} & Sintered \& Rolled; Roll Clad \\
\hline $\mathrm{W} 20 \%$ vol $\mathrm{UO}_{2}$ Dispersion & 650 & {$[5]$} & Sintered \& Rolled; Roll Clad \\
\hline $\mathrm{W} 30 \%$ vol UO $\mathrm{U}_{2}$ Dispersion & $>1000$ & {$[5]$} & Sintered \& Rolled; Roll Clad \\
\hline Uranium Dioxide, $\mathrm{UO}_{2}$ & 1100 & Signs of Plasticity/ [22] & Polycrystalline \\
\hline
\end{tabular}

Table 1: Transition temperatures where plasticity appears for selected materials. Results depend on strain rate, test methods, and sample fabrication.

\section{A. Fracture and Plasticity in Theory}

Fracture mechanics provides an explanation for DBTT. The Griffith theory of fracture strength [18] arose from WWI aeronautical research into contradictory observations in the fracture of brittle materials. Griffith explained fracture as a transfer of the elastic energy of a tensile stress into the surface energy of the formed crack, $G=2 \gamma$. Importantly, beyond a critical crack size, the elastic energy released by a crack is sufficient to provide the crack's surface energy, and the crack can propagate. Below the critical crack size, the elastic energy is insufficient to provide this surface energy, and the crack cannot propagate. This relationship between the critical flaw length, $a$, applied stress $\sigma_{f}$, and total energy dissipated is given by Eqn (2). For brittle materials, such as glass, the model gives good predictions.

$$
\sigma_{f} \sqrt{a}=\sqrt{\frac{E G}{\pi}}
$$

In the absence of plasticity, brittle materials will sustain high stresses near the crack tip. Irwin [23] showed that when plasticity is present, there is plastic deformation near the crack tip due to the high local stresses. In an energy interpretation, the elastic energy stored in the tensile stress is partially dissipated into plastic deformation near the crack tip, and the dissipated energy, $G$, must include another term, $G_{P}$, for energy dissipation due to plastic deformation. With elastic energy dissipated in plastic deformation, less energy is available for the crack's surface energy, and the critical crack size becomes much larger.

$$
G=2 \gamma+G_{P}
$$

For brittle materials, $G_{P} \cong 0 \mathrm{~J} / \mathrm{m}^{2}$ and $\gamma \cong 1 \mathrm{~J} / \mathrm{m}^{2}$ dominates. For ductile materials, $G_{P} \cong 1000 \mathrm{~J} / \mathrm{m}^{2}$. For a fixed stress, the critical crack size, $a$, increases by 500 times as plasticity appears during this transition.

\section{B. DBTT in Cermet Fuel Element Materials}


At room temperature, the brittleness of $\mathrm{W} / 25 \% \mathrm{Re}$ makes it very hard to machine; plastic deformation and failure occur at small strains and high stresses (Figure 8). At higher temperatures, it is very ductile and strains of $50 \%$ are possible. Tungsten has a sharper transition [21] than $\mathrm{W} / 25 \% \mathrm{Re}$. Uranium Dioxide also has a ductile to brittle transition (Figure 8).
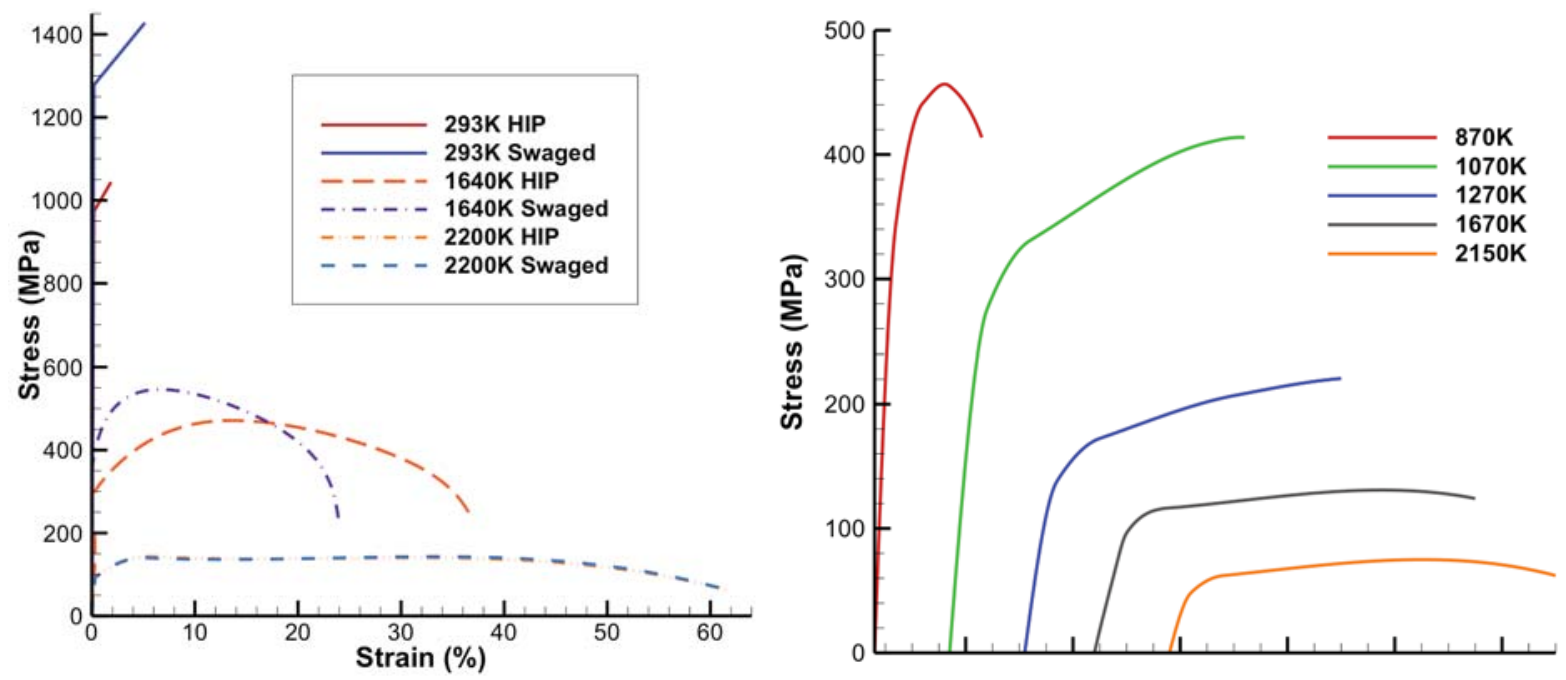

Figure 8. Stress strain curves demonstrate ductile to brittle transition for $W / 25 \%$ Re in tension (left) and $\mathbf{U O}_{2}$ in compression (right). Data from Ref. [26] and [21]. These data are elastic-plastic input for simulations.

\section{DBTT in NERVA Graphite Fuel Element Materials}

NERVA graphite fuel elements do not have simple behavior. Graphite displays brittle to quasi-brittle behavior [24] with little or no plasticity before failure. Strength is widely variable, and acoustic emissions during strain indicate a slow accumulation of slip, cleavage, and microcracking. NERVA graphite fuel elements are not pure

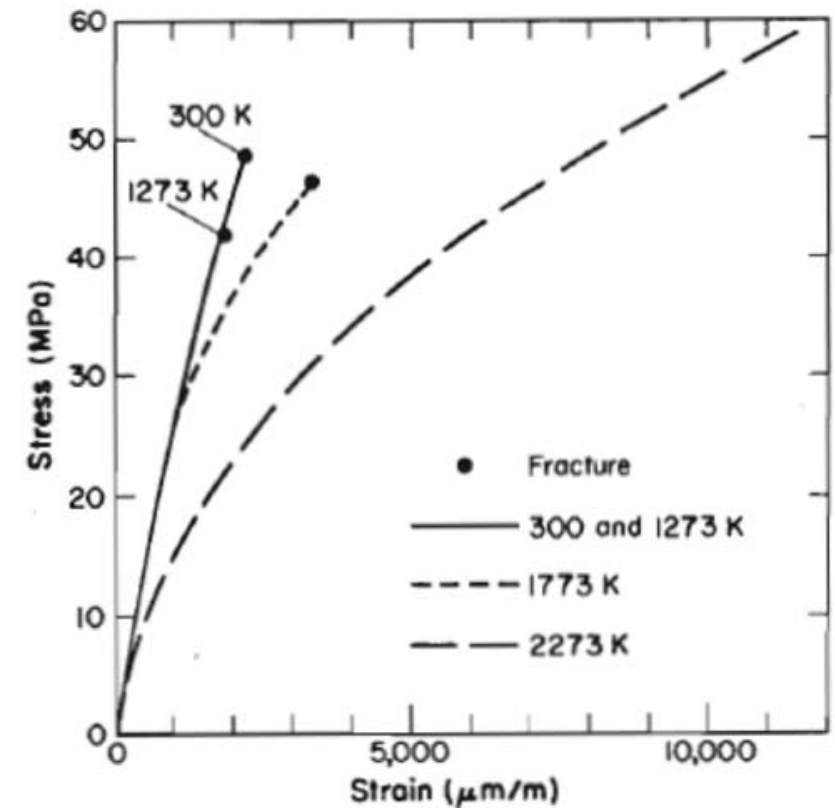

Figure 9. Stress-strain data from room temperature to 2273 K for a (U,Zr)C-graphite composite of 30-vol\% carbide content and $630 \mathrm{~kg} / \mathrm{m}^{3}$ uranium loading. Data from $\operatorname{Ref}[9]$. graphite, hence different properties are expected. Figure 9 shows the stress-strain and fracture behavior of a NERVA fuel element composed of $52.9 \mathrm{wt} \% \mathrm{Zr}, 2.22 \mathrm{wt} \% \mathrm{U}$, and $44.8 \mathrm{wt} \%$ C. Zirconium Carbide is $88.4 \mathrm{wt} \%$ $\mathrm{Zr}$ and $11.6 \mathrm{wt} \% \mathrm{C}$.

Zirconium carbide is hard, brittle, and can catastrophically shatter at room temperature. Lee and Haggerty [19] studied plasticity and creep at the yield point of crystals of zirconium carbide at high temperatures. The critical resolved shear stress is the shear stress, resolved to the slip direction, that initiates slip; this is where plastic deformation begins. Figure 10 summarizes their data for $\mathrm{ZrC}$ crystals in tension. Darolia and Archbold [20] studied the compressive yield strength of polycrystalline ZrC (Figure 10) and found "no observable plastic deformation at temperatures below approximately $1200^{\circ} \mathrm{C} \quad\left(\begin{array}{lll}1470 & \mathrm{~K}\end{array}\right)$, and specimens tested at these lower temperatures fractured catastrophically into small fragments. ... However extensive ductility (was) ... observed at temperatures greater than approximately $1500^{\circ} \mathrm{C}(1770 \mathrm{~K})$.”

9

American Institute of Aeronautics and Astronautics 

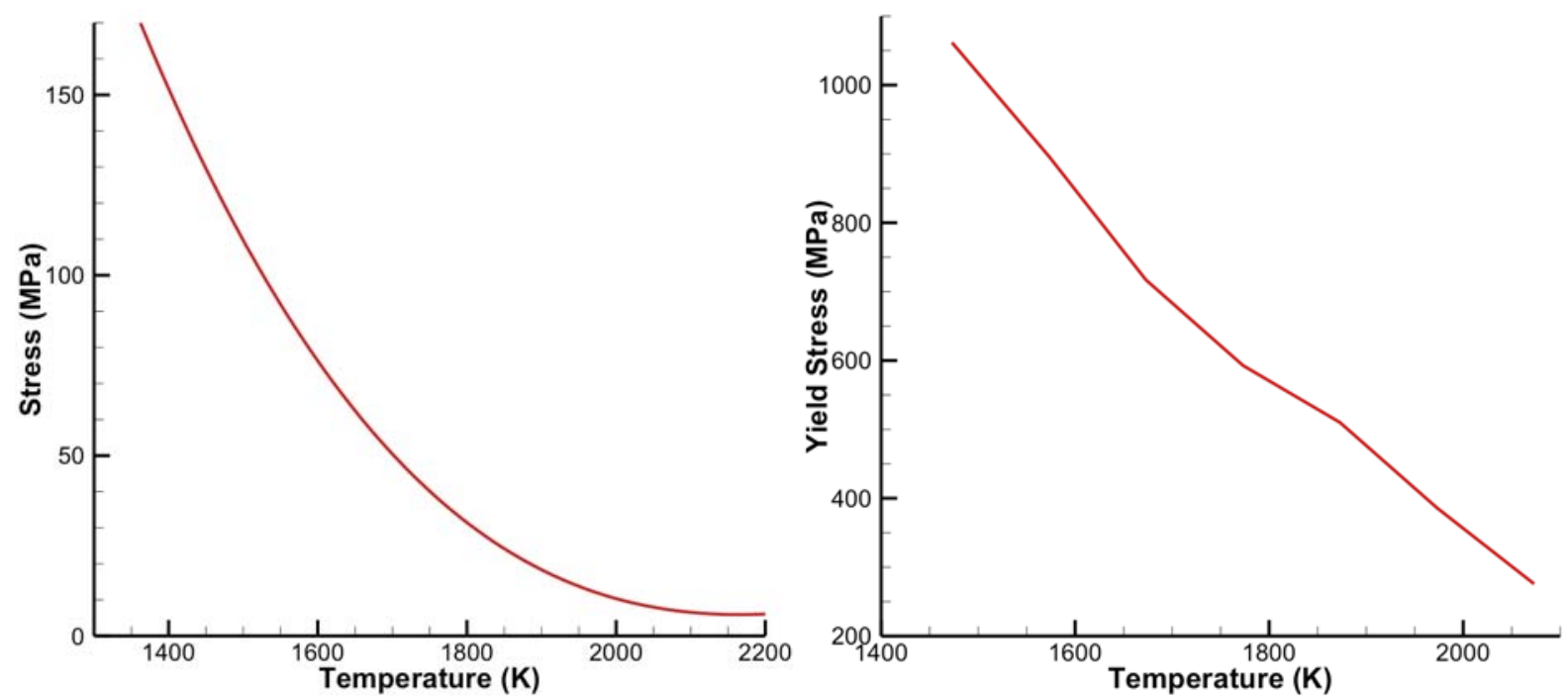

Figure 10. Critical resolved shear stress (tension) for $\mathrm{ZrC}$ crystals (left) and compressive yield strength for polycrystalline $\mathbf{Z r C}$ (right). Data from Refs [19] and [20].

\section{DBTT and Fuel Elements}

What is the effect on fuel elements? Cracking and fracture are much more likely in a brittle region where temperatures are below DBTT. Figure 11 shows the temperature distribution through a $(\mathrm{U}, \mathrm{Zr}) \mathrm{C}$ - graphite fuel element without a tie tube, as in the NF-1 test. While temperatures are below DBTT at the coolant inflow end; as the coolant picks up heat along the element, fuel temperature increases to near melting. Stress sources in the brittle region may make cracks propagate, but in the ductile region, stresses result in plastic deformation.

How can brittle fracture be detected? Fractography of the original NF-1 fuel elements would be insightful. The current numerical simulations use an elastic-plastic model of isotropic Young's modulus, and the model can distinguish plastic deformation. For stress-strain curves at multiple temperatures, this model is elastic up to the yield stress, followed by a plastic stress range. In particular, plastic deformation only occurs beyond the yield point, and brittle fracture is indicted when this plastic strain occurs below the DBTT. For example, Figure 7 shows plastic deformation at temperatures where $\mathrm{ZrC}$ is expected to be brittle. Plastic deformation - and probably brittle fracture-occurs when the fuel element edge is hot (typical), but not when radial temperature variations are minimized.

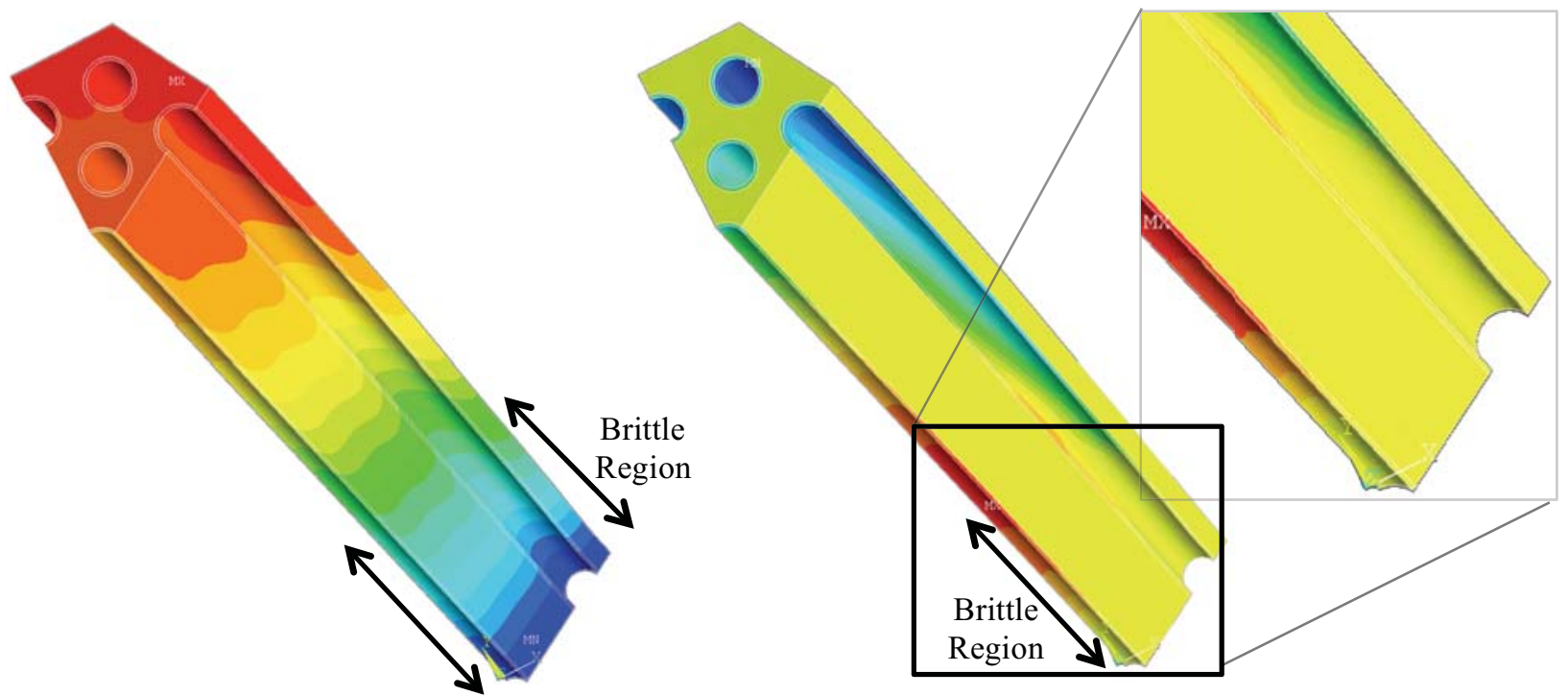

Figure 11. NERVA (U,Zr)C-graphite composite fuel element simulated in NF-1 reactor (no tie tube); temperature (left) and axial component of plastic strain (right). A brittle region for $\mathrm{ZrC}$ would be expected at the cool end where temperatures are below $1500 \mathrm{~K}$. Note that axial plastic strain decreases toward inlet for interior coolant channel as shown in the inset. 
Figure 11 results further support the brittle-ductile explanation for the cracking seen in Figures 1 and 2. The inset graphic shows plastic strain drops to zero at the cold inlet of the center coolant channel, while it increases toward the hot end of the brittle region where temperatures are near $1500 \mathrm{~K}$. A brittle-ductile transition defines the upstream side of the mid-passage erosion region, and a decrease in stress defines the downstream side. The edge coolant channel shows much less plastic deformation, hence fracture is much less likely.

Although the fuel element may not fracture in the ductile region, thermal cycling results in cycles of plastic deformation. On heating, CTE mismatches between fuel and cladding produce stresses and plastic deformations, while on cooling these CTE induced stresses reverse and yield further deformations. Similarly with thermal stresses. Over many thermal cycles, failure was observed in ANL200 testing (Figure 3). Furnace heating will capture the stresses due to CTE mismatch between fuel and cladding, but not thermal stresses. Thermal stresses are due to differential thermal expansion from temperature gradients as heat passes through the fuel into the coolant.

The role of DBTT was recognized in previous cermet fuel element engineering. Researchers at NASA Glenn [5] commented, "Since fuel elements in the TWMR (Tungsten Water Moderated Rocket) probably would not be permitted to operate at temperatures below the ductile-to-brittle transition temperature of the fuel elements, the effects of fuel loading on this transition temperature were determined in a bend test."

\section{Fuel Element Simulation Methods}

Multidisciplinary fluid/thermal/structural/nuclear simulations are extensions of previous papers on the ANL200 fuel element [1] and the NERVA SNRE fuel element [16]. Numerical methods, geometry, material properties are explained in detail there. This section provides a brief summary of the methods, plus an explanation of recent improvements that have been added.

\section{A. Summary of Simulation Methods}

High-fidelity fluid/thermal/structural simulations are performed for a symmetric sector of a single fuel element, as shown in Figure 12. Using symmetry allows the largest part of the physics to be captured at the lowest computational cost. The full length of the fuel element can be simulated, however a short axial section (a "pizza slice") is also simulated for quick sensitivity analysis, as in Figures 5 and 7. Heat deposition rates are derived from MCNP simulations, and include axial, but not radial variations. Fuel element geometry is faithfully reproduced and includes coolant channels and resolves coatings and claddings; temperature dependent material properties are carefully researched and referenced.

The baseline 3D simulation method is ANSYS Multiphysics [25], which combines FLOTRAN for the fluid analysis, ANSYS thermal for the thermal analysis, and ANSYS structural for the stress analysis. FLOTRAN solves
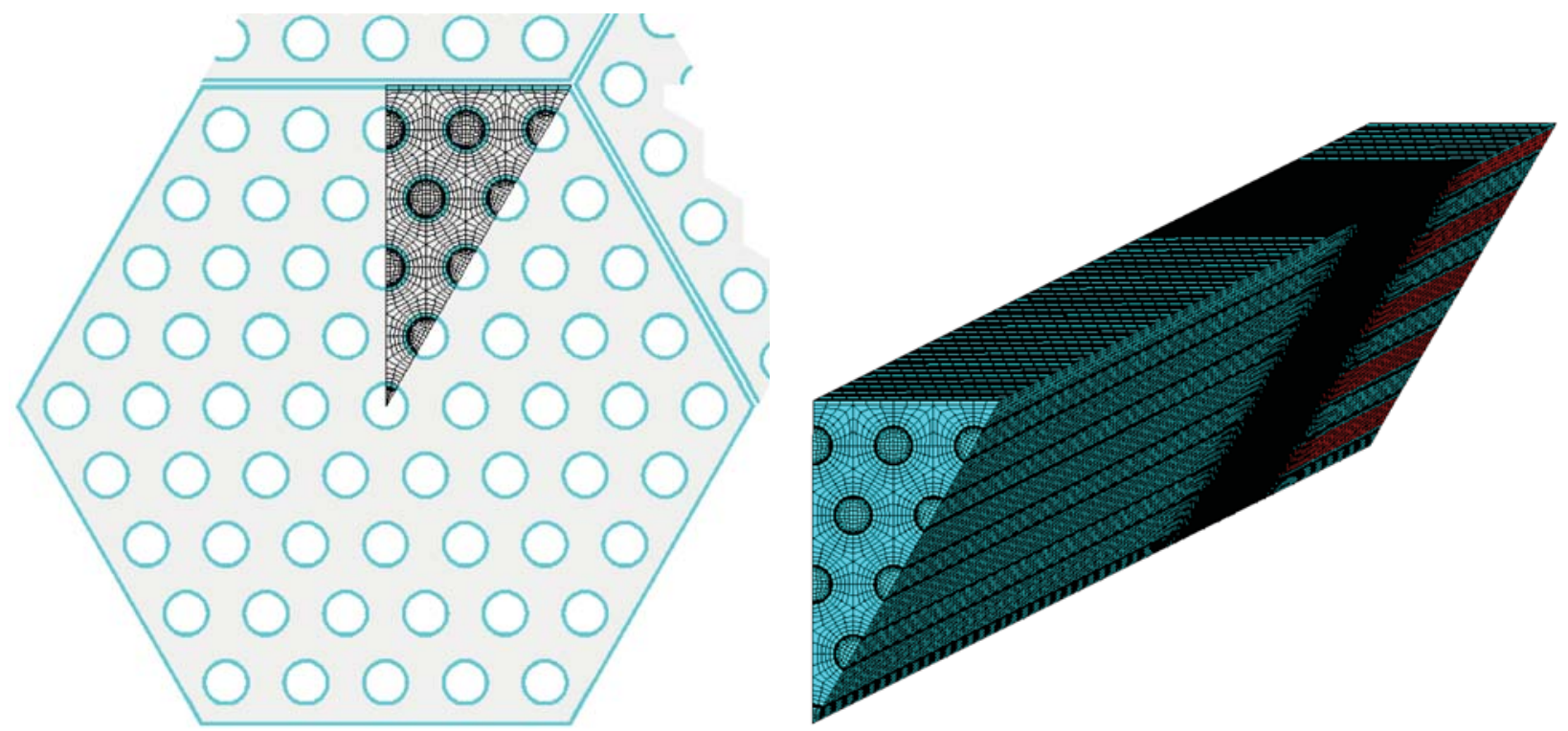

Figure 12. AN200 fuel element cross-section (left) showing grid for symmetric sub-region of reactor core and full-length 3D grid (right). At left, blue is cladding, grey is cermet fuel, and white is coolant channel. At right, red region is $\mathrm{BeO}$ reflector; black region is highly resolved region.

11

American Institute of Aeronautics and Astronautics 
the three-dimensional Reynolds Averaged Navier-Stokes (RANS) equations. Turbulence effects are simulated with the $\kappa-\varepsilon$ turbulence model.

\section{B. Recent Simulation Improvements}

To improve the fluid simulations, the resolution of the fluid boundary layer was increased to $\sim 16$ cells. On the coolant channel walls, grid spacing remains at $y^{+} \cong 1$. The computational cost of this larger simulation is unacceptable; an approximate solution is established on a coarser grid ( $\sim 8$ cells across boundary layer), interpolated to the finer grid, and finished.

Elastic properties have previously been assumed, with a creep model. Recently, elastic-plastic properties for W $125 \mathrm{Re}$ ( [26] and Figure 8), W-50\% $\mathrm{UO}_{2}$ [5], $\left.\mathrm{ZrC} \mathrm{(} \mathrm{[19],} \mathrm{[20],} \mathrm{and} \mathrm{Figure} \mathrm{10),} \mathrm{and} \mathrm{(U,} \mathrm{Zr}\right) \mathrm{C}$ - graphite ( [9] and Figure 9) have been researched and incorporated. This allows better detection of yielding and fracture.

\section{Conclusions}

Stress analysis for NTP fuel elements is significantly different from mainstream structural analysis where stresses must be kept below elastic limits (yield point) by a safe margin, and temperatures are limited. Since the fuel element will have regions near melting temperatures - and creep rates increase dramatically with higher temperature-permanent deformation becomes important for the majority of the fuel element. However, deformation does not occur everywhere.

Zirconium carbide is brittle and prone to shatter below $1500 \mathrm{~K}$. This brittle temperature range is an explanation for the mid-passage erosion observed in NERVA fuel experiments. The role of plasticity in this brittle/ductile behavior is explained here. Cermet fuels also have a brittle to ductile transition; for uranium dioxide particles in a tungsten matrix with $\mathrm{W} / 25 \mathrm{Re}$ cladding, this temperature may be low $(350-530 \mathrm{~K})$ and may provide a significant design advantage over NERVA graphite-based fuel elements. In particular, high stresses may lead to deformation but not cracking of the cermet fuel and cladding. Experiments should carefully examine brittle and ductile behavior. Increasing the CTE of the graphite-based NERVA fuel to match or exceed that of the $\mathrm{ZrC}$ coating is an approach to improving this fuel.

Thermal cycling tests will capture CTE mismatch stresses (at furnace hold temperature), but they will not capture thermal stresses. Also, performance in any brittle region will not be captured if it is a brief transient during the thermal cycle.

In experiments, the coolant flow in channels should be measured (directly or indirectly) and the orificing of individual fuel element coolant channels should be carefully considered.

Careful measurements of the structural properties of reactor materials would improve these simulations, help interpret experimental results, and advance NTP development.

\section{Acknowledgments}

The authors would like to thank Stan Borowski for his guidance and support. They also thank Raj Sai, Marc Freedman, Louis Ghosn, Dan Kosareo, and Jim Fittje for many helpful discussions, as well as, John Warren and Chris Moore (NASA Headquarters), and Mike Houts (MSFC) who supported this work through the Advanced Exploration Systems Program and its Nuclear Cryogenic Propulsion Stage (NCPS) Project. Additional funding was provided by NASA Glenn Research Center and the Department of Energy's Idaho National Laboratory. The GRC library staff tirelessly located many documents, journal articles, and reports.

\section{References}

[1] M. E. M. Stewart and B. G. Schnitzler, "Thermal, Fluid, and Structural Analysis of a Cermet Fuel Element," in 48th Joint Propulsion Conference, AIAA 2012-3959, Atlanta GA, August 2012.

[2] D. R. Koenig, "Experience Gained from the Space Nuclear Rocket Program (Rover)," LA-10062-H, Los Alamos National Lab., Los Alamos, NM, May 1986.

[3] J. M. Taub, "A Review of Fuel Element Development for Nuclear Rocket Engines," Los Alamos National Lab., LA-5931, Los Alamos, NM, June 1975.

[4] Argonne National Laboratory, "Nuclear Rocket Program Terminal Report," ANL-7236, Argonne, IL, 1968.

[5] N. T. Saunders, R. E. Gluyas and G. K. Watson, "Feasibility Study of a Tungsten Water-Moderated Nuclear Rocket, II Fueled Materials," NASA TM X-1421, 1968. 
[6] D. R. deHalas, A. F. Lietzke, N. T. Saunders, C. P. Blankenship, R. E. Gluyas and G. K. Watson, "Reactor and Materials Technology Department: Tungsten-Uranium Dioxide Cermet Research and Development Activities," NASA-CR-54409, BNWL-110, 1965.

[7] General Electric, Nuclear Materials and Propulsion Operation, "710 High-Temperature Gas Reactor Program Summary Report; Volumes I-VI," GEMP-600, Vol 1 to 6, 1968.

[8] C. Haertling and R. J. Hanrahan, "Literature Review of Thermal and Radiation Performance Parameters for High-Temperature, Uranium Dioxide Fueled Cermet Materials," Journal of Nuclear Materials, vol. 366, pp. 317-335, 2007.

[9] L. L. Lyon, "Performance of (U, Zr)C-Graphite (Composite) and of (U, Zr)C (Carbide) Fuel Elements in the Nuclear Furnace 1 Test Reactor,” LA-5398-MS, Los Alamos Scientific Laboratory, Los Alamos, 1973.

[10] L. W. Kirk, "Nuclear Furnace-1 Test Report," Los Alamos Scientific Laboratory, Los Alamos, NM, LA-5189MS, March 1973.

[11] General Electric, Nuclear Materials and Propulsion Operation (NMPO), "710 High-Temperature Gas Reactor Program Summary Report: Volume III-Fuel Element Development," GEMP-600, Vol. III, 1968.

[12] J. E. Battles, R. K. Edwards, G. E. Gunderson and W. A. Shinn, "Tungsten Cladding of W-UO2 NuclearRocket Fuel Subsections by Vapor Deposition," ANL-7235, Argonne National Lab., Dec. 1967.

[13] Argonne National Laboratory, "Nuclear Rocket Program Quarterly Progress Report, Fourth Quarter 1965," ANL-7150, Argonne, IL, 1965.

[14] R. J. Buzzard and F. L. Gill, "High-Temperature Mechanical Properties of a Tungsten-Uranium Dioxide Composite," NASA TM X-1018, Lewis Research Center, Cleveland, OH, 1964.

[15] R. J. Beals, J. H. Handwerk and B. J. Wrona, "Behavior of Urania-Rare-Earth Oxides at High Temperatures," Journal of the American Ceramic Society, vol. 52, no. 11, pp. 578-581, Nov. 1969.

[16] M. E. M. Stewart and B. G. Schnitzler, "Thermal Hydraulics and Structural Analysis of the Small Nuclear Rocket Engine (SNRE) Core," in 43rd Joint Propulsion Conference, AIAA 2007-5619, Cincinnati, July 2007.

[17] F. P. Durham, "Nuclear Engine Definition Study Preliminary Report Vol. 1-3," LA-5044-MS, Los Alamos National Lab., Los Alamos, Sept 1972.

[18] A. A. Griffith, "The Phenomena of Rupture and Flow in Solids," Philosophical transactions of the royal society of london, Series A, vol. 221, pp. 163-198, 1921.

[19] D. W. Lee and J. S. Haggerty, "Plasticity and Creep in Single Crystals of Zirconium Carbide," Journal of the American Ceramic Society, vol. 52, no. 12, pp. 641-647, Dec 1969.

[20] R. Darolia and T. F. Archbold, "Plastic deformation of polycrystalline zirconium carbide," Journal of Materials Science, vol. 11, pp. 283-290, 1976.

[21] P. L. Raffo, "Yielding and Fracture in Tungsten and Tungsten-Rhenium Alloys," NASA TN D-4567, May 1968.

[22] J. F. Bryon, "Yield and Flow of Polycrystalline Uranium Dioxide," Journal of Nuclear Materials, vol. 27, no. 1, pp. 48-53, 1968.

[23] G. R. Irwin, "Analysis of Stresses and Strains Near the End of a Crack Traversing a Plate," Journal of Applied Mechanics, pp. 361-364, 1957.

[24] N. N. Nemeth and R. L. Bratton, "Statistical Models of Fracture Relevant to Nuclear-Grade Graphite: Review and Recommendations," NASA/TM-2011-215805, NASA, Cleveland, OH, March 2011.

[25] ANSYS, "ANSYS Multiphysics Software, Ver. 10.0," ANSYS Inc., Cannonsburg, PA, 2006.

[26] T. Leonhardt, "Properties of Tungsten-Rhenium and Tungsten-Rhenium with Halfnium Carbide," JOM; The Journal of the Minerals, Metals \& Materials Society, vol. 61, no. 7, pp. 68-71, 2009.

[27] Y. S. Touloukian, Thermophysical Properties of Matter, vol. 2, New York: IFF/Plenum, 1970.

[28] J. K. Fink, M. G. Chasanov and L. Leibowitz, “Thermophysical Properties of Uranium Dioxide,” Journal of Nuclear Materials, vol. 102, pp. 17-25, 1981.

[29] M. O. Marlowe and A. I. Kaznoff, "Development of Low Thermal Expansion Tungsten-UO2 Cermet Fuel," NASA CR-72711, General Electric Company, 1970. 